\title{
CONSERVAÇÃO REFRIGERADA DE LIMA ÁCIDA 'TAHITI': USO DE 1-METILCICLOPROPENO, ÁCIDO GIBERÉLICO E CERA ${ }^{1}$
}

\author{
MARIA LUIZA LYE JOMORI², RICARDO ALFREDO KLUGE³ ${ }^{3}$ ANGELO PEDRO JACOMINO ${ }^{4}$, SILVIO TAVARES ${ }^{5}$
}

\begin{abstract}
RESUMO - A conservação refrigerada da lima ácida 'Tahiti' sob baixa temperatura permite o aumento no período de comercialização dos frutos, entretanto, a perda da coloração verde da casca é o principal entrave que impede este prolongamento. O objetivo do presente trabalho foi verificar o efeito da aplicação do 1-metilciclopropeno (1-MCP), associado ao uso de cera e ácido giberélico (GA), sobre a conservação refrigerada de lima ácida 'Tahiti'. Foram aplicados os tratamentos: T1:Controle; T2: 1-MCP $\left(1 \mathrm{mg} . \mathrm{L}^{-1}\right)$ durante 12 horas a 20두 $\mathrm{T} 3$ : Cera (0,1 mL por fruto); T4: Ácido giberélico - GA (10 mg. L $\left.{ }^{-1}\right)$; T5: 1-MCP + Cera; T6: 1-MCP + GA; T7: Cera + GA; T8: 1-MCP + Cera + GA; T9: T2 + re-aplicação de 1-MCP após 30 dias de armazenamento. Os frutos foram armazenados durante 30 e 60 dias a $10^{\circ} \mathrm{C} \mathrm{e} 90 \%$ UR. A cera foi suficiente para retardar a perda de coloração verde da casca até 30 dias de conservação a $10^{\circ} \mathrm{C}$. O 1-MCP também mantém a coloração verde até 30 dias de conservação refrigerada, enquanto que a sua reaplicação após este período não apresenta efeito para a manutenção da coloração verde da casca. No presente trabalho não foi pronunciado o efeito do ácido giberélico. Após 60 dias de armazenamento os frutos não se apresentavam comercializáveis.
\end{abstract}

Termos para indexação: Citrus latifolia, desverdecimento, etileno, pós-colheita.

\section{COLD STORAGE OF 'TAHITI’ LIME: USE OF 1-METHYLCYCLOPROPENE, GIBBERELLIC ACID AND WAX}

ABSTRACT - The storage of 'Tahiti' lime under low temperatures allows the marketing period to be extended, however the loss of the green skin colour prevent such improvement to be achieved. The purpose of this research was to verify the efficiency of 1-methylcyclopropene (1-MCP) associated with the use of gibberellic acid (GA) and wax during the cold storage of 'Tahiti' lime. The treatments used were: T1: fruit without treatment (control); T2: 1-MCP (1,0 i L. L-1 $)$ during $12 \mathrm{~h}$ at 20 ${ }^{\circ} \mathrm{C}$; T3: wax $\left(0,1 \mathrm{~mL}\right.$ per fruit); T4: GA (10 mg. $\left.\mathrm{L}^{-1}\right)$; T5: 1-MCP + wax; T6: 1-MCP + GA; T7: wax + GA; T8: 1-MCP + wax + GA; T9: T2 + new application of 1-MCP after 30 days of storage. Fruit were stored during 30 and 60 days at $10^{\circ} \mathrm{C}$ and $90 \% \mathrm{RH}$. The wax application was sufficient for the maintenance of green skin colour after 30 days of cold storage. 1-MCP maintain the green skin colour up to 30 days of cold storage, while new application of 1-MCP after this period does not present effect for the maintenance of colour. After 60 days of storage the fruit did not become marketable.

Index terms: Citrus latifolia, degreening, ethylene, postharvest.

\section{INTRODUÇÃO}

A lima ácida 'Tahiti' apresenta peculiaridades quanto à sua comercialização, se comparada com outras frutas cítricas. Entre elas, a manutenção da cor verde da casca, que é extremamente desejável durante toda a vida útil pós-colheita desta fruta. O aparecimento da coloração amarela, total ou parcialmente, reduz sua aceitação pelo mercado consumidor.

Na prática, esta fruta é colhida com coloração verde, após alcançar o pleno desenvolvimento, e comercializada enquanto a cor da casca permanece nesta condição. Entretanto, os processos de degradação da clorofila e síntese de carotenóides continuam ocorrendo mesmo durante a comercialização sob condições ambientais e culminam com o desverdecimento da fruta. Mesmo sob refrigeração, estas alterações continuam ocorrendo, embora mais lentamente (Baldwin, 1994).

As condições recomendadas para a conservação refrigerada de lima 'Tahiti' são temperatura entre 10 e $12^{\circ} \mathrm{C}$ e umidade relativa(UR) entre $85-95 \%$. Nestas condições os frutos podem ser armazenados por 4 a 8 semanas. Longos períodos de temperatura abaixo de $8^{\circ} \mathrm{C}$ induzem o aparecimento de injúrias pelo frio, caracterizadas por depressões superficiais e aumento na incidência de doenças (Chitarra \& Chitarra, 1990; Kluge et al., 2001).

Alguns tratamentos auxiliares à refrigeração têm sido testados ou aplicados em lima 'Tahiti', visando à manutenção da coloração verde da casca e aumento no período de transporte e comercialização. Estes tratamentos incluem o uso de reguladores vegetais e cera.

A giberelina é um hormônio relacionado a juvenilidade, ao contrário do etileno e ácido abscísico, que são hormônios ligados à senescência, portanto antagônicos a giberelina (Dilley, 1969). Assim, a aplicação de giberelina pode adiar processos relacionados com o enve- lhecimento e senescência do fruto, incluindo a degradação da clorofila (Schechter et al., 1989). Barros et al. (1991) aplicaram ácido giberélico (GA) em lima 'Tahiti', na concentração de 40mg. $\mathrm{L}^{-1}$, tendo verificado um retardamento no aparecimento de coloração amarela dos frutos. Os autores observaram que o desverdecimento dos frutos tratados começou a ocorrer após 35 dias de conservação refrigerada, enquanto que nos frutos controle este processo iniciou-se aos 7 dias. Silva \& Donadio (1997) apontam o tratamento com GA (20mg. $\left.\mathrm{L}^{-1}\right)$ como uma obrigatoriedade para a exportação desta espécie cítrica, como forma de manter a cor verde da casca e retardar o envelhecimento do fruto durante o transporte. Spósito et al. (2000) trataram limas 'Tahiti' com GA (10mg.L-1), tendo observado manutenção da coloração da casca dos frutos por até 45 dias a $11^{\circ} \mathrm{C}$.

$\mathrm{O}$ uso de ceras tem objetivo de reduzir a perda de massa (umidade) e, conseqüentemente, o amolecimento e o murchamento. A aplicação de cera também tem por finalidade dar maior brilho à fruta, melhorando a qualidade visual da mesma (Kaplan, 1986). Apresenta também uma ação antifúngica e minimiza desordens na casca e colapso do tecido próximo ao pecíolo (Waks et al., 1985). Em limas armazenadas a $8-10^{\circ} \mathrm{Ce}$ 80-95\% de UR, foi constatada redução na perda da umidade após o armazenamento (Fioravanço, 1992).

O 1-MCP (1-metilciclopropeno) é um composto gasoso que tem demonstrado ser um eficiente inibidor da ação do etileno. O 1-MCP se liga ao sítio de recepção do etileno, atuando como antagonista. Esta substância apresenta grande potencial de aplicação comercial para o controle da maturação de frutas e hortaliças, e da senescência de flores (Sisler \& Serek, 1997).

Embora frutos não climatéricos, como os citros, apresentem apenas o sistema 1 de produção de etileno, ou seja, baixa produção de etileno (Vendrell \& Palomer, 1997), isso não implica que não haja interferência do etileno sobre a maturação do fruto. Goldschmidt (1997) afirma

\footnotetext{
${ }^{1}$ (Trabalho 051/2003). Recebido: 07/02/2003. Aceito para publicação: 11/09/2003.

${ }^{2}$ Aluna de graduação em Engenharia Agronômica da ESALQ/USP, Bolsista da FAPESP.

${ }^{3} \mathrm{Eng}^{\circ} \mathrm{Agr}^{\mathrm{o}}$, Professor do Dep.Ciências Biológicas da ESALQ/USP. C.P. 9 13418-900 Piracicaba, SP Bolsista do CNPq. rakluge@esalq.usp.br < Autor correspondente>

${ }^{4} \mathrm{Eng}^{\mathrm{O}} \mathrm{Agr}{ }^{\circ}$, Professor do Dep. Produção Vegetal, ESALQ/USP. Bolsista do CNPq. jacomino@esalq.usp.br

${ }^{5}$ Eng $^{\circ} \mathrm{Agr}^{\circ}, \mathrm{MSc}$, doutorando do curso de Fitotecnia da ESALQ/USP.
} 
que o etileno, mesmo que em baixa concentração em frutos não climatéricos, está envolvido em eventos associados à maturação, como a degradação da clorofila da casca. Assim, é possível que a aplicação do 1-MCP retarde o desverdecimento da casca de lima ácida, devido a sua influência na ação do etileno. Já foi constatado que o 1-MCP aumentou a conservação de morangos (Ku et al., 1999), um fruto tipicamente não climatérico. Além disso, o 1-MCP tem retardado o amadurecimento de produtos climatéricos (Blankenship \& Dole, 2003).

A partir destas considerações o objetivo do presente trabalho foi de avaliar o efeito do 1-MCP, associado ao uso de ácido giberélico e cera, durante a conservação refrigerada de lima 'Tahiti', visando ampliar seu período de armazenamento.

\section{MATERIAL E MÉTODOS}

A colheita foi realizada em pomar comercial, localizado no município de Mogi-Guaçu, SP, sendo os frutos transportados imediatamente para o Laboratório de Pós-colheita do Departamento de Ciências Biológicas da ESALQ/USP. Foram utilizados frutos com diâmetro médio de $50 \mathrm{~mm}(+3 \mathrm{~mm})$ e com coloração verde intenso. Após a seleção, os frutos foram submetidos aos seguintes tratamentos: T1: Controle: frutos sem nenhum tratamento;T2: frutos submetidos ao tratamento com 1-MCP; T3: frutos submetidos à aplicação de cera; T4: frutos submetidos à aplicação de ácido giberélico (GA); T5: 1-MCP + Cera; T6: 1-MCP + GA; T7: GA + Cera; T8: 1-MCP + GA + Cera e T9: T2 + reaplicação de 1-MCP após 30 dias de armazenamento.

A aplicação de cera à base de polietileno (Citrosolß) foi na proporção de $0,1 \mathrm{~mL}$ por fruto, correspondendo a $1 \mathrm{~L} \cdot \mathrm{t}^{-1}$, feita manualmente, com auxílio de uma pipeta graduada. A aplicação de ácido giberélico foi feita através de imersão dos frutos em solução contendo $10 \mathrm{mg}$. $\mathrm{L}^{-1} \mathrm{de}$ GA, durante 10 segundos, seguindo-se de uma secagem em ar ambiente por 30 minutos. E a aplicação do 1-MCP foi realizada em caixas plásticas herméticas, com capacidade de 1880 litros. Para gerar a concentração de 1,0mg. $\mathrm{L}^{-1}$ foi utilizado o produto comercial SmartFresh ${ }^{\mathrm{TM}}$, na forma de pó molhável, contendo $0,14 \%$ de ingrediente ativo 1-MCP. Assim, quantidades de SmartFresh ${ }^{\mathrm{TM}}$ pré-determinadas foram pesadas e colocadas em frascos com tampa. Adicionou-se a estes frascos $20 \mathrm{~mL}$ de água destilada aquecida a $50^{\circ} \mathrm{C}$, agitando-os até a completa dissolução. Os frascos foram abertos no interior das câmaras, as quais foram fechadas imediatamente para evitar a perda do gás. Os frutos ficaram expostos ao tratamento durante 12 horas sob temperatura de $20^{\circ} \mathrm{C}$.

O delineamento experimental adotado foi inteiramente ao acaso, com nove tratamentos e quatro repetições de dez frutos por parcela.

Os frutos foram armazenados a $10^{\circ} \mathrm{C}$ durante 30 e 60 dias, sendo que após cada período de armazenamento, os mesmos foram colocados em temperatura ambiente $\left(20^{\circ} \mathrm{C}\right)$ durante três dias, sendo então avaliados.

As análises realizadas foram: a) coloração da casca: através do
Minolta Chroma Meter CR-300, sendo determinados os valores de ângulo de cor $\left(\mathrm{h}^{\circ}\right)$ e chroma $\left(\mathrm{C}^{*}\right)$; b) perda de massa: foi determinada pela diferença, em $\%$, entre a massa inicial e a massa após tratamentos e armazenamento; c) taxa respiratória: amostras de 10 frutos foram colocadas em jarros de vidro com capacidade de $5 \mathrm{~L}$, permanecendo hermeticamente fechados por períodos de três horas. Em cada tampa dos jarros foi colocado um septo de borracha através do qual foi retirada a amostra de gás. Com uma seringa de $1 \mathrm{~mL}$ foi coletada uma amostra de cada jarro e injetada em analisador de $\mathrm{CO}_{2}$ Dansensor CR300. Os resultados foram expressos em mL de CO $\mathrm{Cg}_{2}^{-1} \cdot \mathrm{h}^{-1} ; \mathrm{d}$ ) porcentagem de suco: cada repetição foi pesada e, em seguida, extraído o suco dos frutos. A porcentagem de suco foi calculada através da fórmula: $\%$ de suco $=(M S / M F)$ x 100, onde MS $=$ massa do suco $(\mathrm{g})$ e MF $=$ massa do fruto; e) teor de sólidos solúveis totais (SST): determinado em refratômetro digital, com os resultados expressos em ${ }^{\circ}$ Brix; f) acidez total titulável (ATT): a $10 \mathrm{~mL}$ do suco foram adicionados $90 \mathrm{~mL}$ de água destilada, sendo realizada titulação com $\mathrm{NaOH} 1 \mathrm{~N}$ até $\mathrm{pH} 8,10$. Os resultados foram expressos \% (g de ácido cítrico/100ml da amostra); g) "ratio": calculado pela divisão do teor de SST pelaATT; h) índice tecnológico (I.T.): calculado através da fórmula: I.T. $=($ SST $x \%$ de suco $) / 100$; i) teor de vitamina C: uma alíquota de $10 \mathrm{~mL}$ de suco foi colocada em erlenmeyer contendo $50 \mathrm{~mL}$ de solução de ácido oxálico a $1 \%$. A titulação foi efetuada com DCFI (2,6-diclorofenol indofenol) até atingir a coloração rosada persistente por 15 segundos. Os resultados foram expressos em mg de ácido ascórbico/100mL de suco.

Os dados coletados foram submetidos à análise de variância (Teste F) e, em caso de significância as médias foram comparadas pelo teste de Tukey a $5 \%$ de probabilidade.

\section{RESULTADOS E DISCUSSÃO}

Após 30 dias de armazenamento os frutos do tratamento controle apresentaram maior perda de coloração verde em relação aos demais tratamentos, tendo sido observados valores menores do ângulo de cor $\left(h^{\circ}\right)$ e valores maiores de croma para estes frutos sem tratamento (Tabela 1). Valores de $\mathrm{h}^{\circ}$ mais distantes de $90^{\circ}$ representam frutos mais verdes ao passo que, quanto mais próximos a $90^{\circ}$, mais amarelos são os frutos. O croma define a intensidade da cor, assumindo valores próximos a zero para cores neutras (cinza) e ao redor de 60 para cores vívidas (McGuire, 1992). Assim, no presente trabalho, maiores valores de croma significaram maior intensidade da cor amarela. Tanto o 1-MCP quanto o ácido giberélico e a cera, isoladamente ou em conjunto, reduziram a perda de coloração. Em relação ao ácido giberélico os resultados encontrados são semelhantes aos observados por Spósito et al. (2000).

Os frutos tratados com cera apresentaram menor perda de massa (Tabela 1), devido, principalmente à diminuição da perda de água. Frutos não tratados ou tratados apenas com GA ou 1-MCP, por sua vez, obtiveram maiores valores para perda de massa. De fato, efeitos isolados do 1MCP ou GA não eram esperados para esta variável, considerando que

TABELA 1 - Efeito de diferentes tratamentos sobre a perda de massa, teor de sólidos solúveis (SST), porcentagem de suco, acidez total titulável e cor da casca de lima ácida 'Tahiti' após 30 dias de armazenamento $\left(+3\right.$ dias a $\left.20^{\circ} \mathrm{C}\right) .{ }^{1}$

\begin{tabular}{|c|c|c|c|c|c|c|}
\hline \multirow[t]{2}{*}{ Tratament os } & \multicolumn{2}{|c|}{ Cor da casca } & \multirow{2}{*}{$\begin{array}{c}\text { Perda de massa } \\
(\%)\end{array}$} & \multirow{2}{*}{$\begin{array}{c}\% \\
\text { de suco } \\
\end{array}$} & \multirow{2}{*}{$\begin{array}{c}\text { SST } \\
\left({ }^{\circ} \text { Brix }\right) \\
\end{array}$} & \multirow{2}{*}{$\begin{array}{r}\text { Acidez total } \\
\text { Titulável (\%) }\end{array}$} \\
\hline & Ângulo de cor $\left(\mathrm{h}^{\circ}\right)$ & Croma & & & & \\
\hline Controle & $113,50 \mathrm{~d}$ & $38,50 \mathrm{a}$ & $11,50 \mathrm{a}$ & 8,75 & $37,75 \mathrm{c}$ & 6,0 \\
\hline 1-MCP & $117,50 \mathrm{c}$ & $32,00 \mathrm{~b}$ & $12,00 \mathrm{a}$ & 8,25 & $41,00 \mathrm{abc}$ & 6,0 \\
\hline Cera & $121,00 \mathrm{abc}$ & $26,00 \mathrm{~cd}$ & $5,75 \mathrm{c}$ & 8,00 & $31,75 \mathrm{abc}$ & 6,0 \\
\hline GA & $118,25 \mathrm{bc}$ & $31,50 \mathrm{~b}$ & $10,75 \mathrm{a}$ & 8,25 & $38,50 \mathrm{bc}$ & 6,5 \\
\hline $1-\mathrm{MCP}+$ cera & $121,25 \mathrm{ab}$ & $24,75 \mathrm{~d}$ & $5,75 \mathrm{c}$ & 8,50 & $41,75 \mathrm{abc}$ & 6,0 \\
\hline 1-MCP + GA & $118,00 \mathrm{bc}$ & $30,75 \mathrm{bc}$ & $10,50 \mathrm{a}$ & 8,25 & $48,75 \mathrm{a}$ & 7,0 \\
\hline Cera + GA & $121,00 \mathrm{abc}$ & $26,00 \mathrm{~cd}$ & $7,50 \mathrm{~b}$ & 8,25 & $46,25 \mathrm{abc}$ & 6,0 \\
\hline $1-\mathrm{MCP}+$ cera $+\mathrm{GA}$ & $122,25 \mathrm{a}$ & $23,75 \mathrm{~d}$ & $6,25 \mathrm{bc}$ & 8,25 & $46,00 \mathrm{abc}$ & 7,0 \\
\hline Reaplicação 1-MCP & $121,25 \mathrm{ab}$ & $26,75 \mathrm{bcd}$ & $11,75 \mathrm{a}$ & 8,50 & $47,00 \mathrm{ab}$ & 7,0 \\
\hline Teste F & $* *$ & $* *$ & $* *$ & NS & $*$ & NS \\
\hline C.V. $(\%)$ & 1,26 & 7,91 & 7,56 & 5,88 & 8,34 & 7,97 \\
\hline
\end{tabular}

${ }^{1}$ Médias seguidas de mesma letra na coluna não diferem entre si pelo teste de Tukey a 5\%.

$\mathrm{NS}, *, * *$ teste $\mathrm{F}$ não significativo ou significativo a 1 ou $5 \%$, respectivamente. 
possuem efeitos diferentes da cera. A perda de massa pela transpiração ocorre principalmente da água existente nas células da casca, flavedo e albedo dos frutos. Considerando que a cera promove um revestimento sobre a casca dos frutos, bloqueia os estômatos e de certa forma, promove uma modificação das trocas gasosas dos frutos, sua eficiência na redução da transpiração é maior (Petracek et al., 1998). Resultados semelhantes com uso de cera foram obtidos por Fioravanço (1992).

De modo geral, os tratamentos não interferiram na taxa respiratória, teor de sólidos solúveis totais, acidez total titulável, 'ratio', índice tecnológico e teor de vitamina C (Tabelas 1 e 2). A porcentagem de suco foi menor em frutos tratados com cera, embora não tenha diferido significativamente do controle e dos frutos tratados com GA e 1-MCP. Este resultado é explicado devido ao fato de que, como houve menor perda de massa do fruto tratado com cera, houve menor proporção de suco em relação à massa total do fruto.

Os frutos não se apresentavam comercializáveis após 60 dias de conservação, principalmente devido à presença de odor e sabor estranhos e a perda da coloração verde da casca de alguns tratamentos, que provocaram a perda da coloração semelhante ao controle, como foi o caso do 1-MCPe GA(Tabela 3). A cera reduziu a perda da cor verde em relação ao controle e aos tratamentos isolados de 1-MCP e GA, ao passo que a reaplicação de 1-MCP não favoreceu a manutenção da coloração verde.

De igual forma ao verificado após 30 dias de conservação, poucas alterações físico-químicas ocorreram nos frutos após 60 dias de armazenamento (Tabela 4), à exceção da perda de massa que foi menor em frutos tratados com cera.

Um dos grandes entraves que impedem um maior período de conservação e comercialização de lima 'Tahiti' é a perda de coloração verde da casca. Neste sentido têm-se buscado tratamentos adicionais à refrigeração que evitem o desverdecimento dos frutos. Observa-se, na prática, que o ácido giberélico é muito utilizado no caso de exportação, sendo que seu modo de ação está em atrasar a senescência do fruto por ser antagônico ao etileno. Mesmo em frutos não climatéricos, como a lima 'Tahiti', o etileno produzido em baixas concentrações parece regular o processo de senescência, incluindo a taxa de degradação de clorofila (Goldschmidt, 1997). A aplicação de ácido giberélico aumenta os níveis endógenos desse hormônio e parece retardar os efeitos do etileno na senescência (Dilley, 1969; Abeles et al., 1997).

O 1-MCP tem mostrado ser um inibidor efetivo da ação do etileno, ligando-se ao sítio do mesmo e impedindo os seus efeitos (Sisler \& Serek, 1997). O 1-MCP tem sido aplicado com êxito em frutos climatéricos como forma de retardar o amadurecimento (Blankenship \& Dole, 2003). Embora a lima 'Tahiti' seja um fruto não climatérico, tem sido relatado que o etileno produzido, mesmo que em baixas concentrações, pode regular a sua taxa de senescência (Goldschmidt, 1997). Neste sentido, o uso de bloqueadores de etileno poderia também reduzir a senescência deste fruto. Em brócolis, por exemplo, foi verificado que a aplicação de 1-MCP retardou a perda de coloração verde, estando isso associado com menor atividade da clorofilase (Ku et al., 1999; Fan \& Mattheis, 2000). No caso da lima 'Tahiti', as alterações indesejáveis estão associadas também com o desverdecimento. Sendo assim, é possível que o 1-MCP tenha reduzido indiretamente a atividade da clorofilase, através do bloqueio da ação do etileno. Por outro lado, esperava-se que a reaplicação do 1-MCP após 30 dias de conservação pudesse preservar a coloração dos frutos até 60 dias, o que não ocorreu. Possivelmente novos sítios receptores de etileno foram produzidos durante o armazenamento, permitindo a ação do hormônio na indução da senescência. Sabe-se que os sítios receptores do etileno são complexos protéicos identificados em Arabidopsis talhiana como ETR1, sendo estes sintetizados durante a senescência de plantas e frutos (Taiz \&

TABELA 2 - Efeito de diferentes tratamentos sobre o teor de vitamina C, taxa respiratória (TR), índice tecnológico e "ratio" de lima ácida "Tahiti' após 30 dias de armazenamento $\left(+3\right.$ dias a $\left.20^{\circ} \mathrm{C}\right) .{ }^{1}$

\begin{tabular}{|c|c|c|c|c|}
\hline Tratamentos & $\begin{array}{l}\text { Taxa respiratória } \\
\left(\mathrm{mL} \text { de } \mathrm{CO}_{2} \mathrm{~kg}^{-1} \mathrm{~h}^{-1}\right)\end{array}$ & $\begin{array}{l}\text { Índice tecnológico } \\
(\mathrm{SST} \times \mathrm{x} \% \text { suco }) / 100\end{array}$ & "Ratio" & $\begin{array}{c}\text { Vitamina } \mathrm{C} \\
\left(\mathrm{mg} \text { ácido ascórbico } / 100 \mathrm{~mL}^{-1}\right)\end{array}$ \\
\hline Controle & 24,93 & 3,00 & 1,345 & 26,75 \\
\hline 1-MCP & 27,86 & 3,25 & 1,335 & 25,00 \\
\hline Cera & 18,84 & 3,00 & 1,305 & 25,00 \\
\hline GA & 23,86 & 2,75 & 1,250 & 26,75 \\
\hline 1-MCP + Cera & 19,32 & 3,00 & 1,320 & 23,00 \\
\hline $1-\mathrm{MCP}+\mathrm{GA}$ & 23,63 & 3,75 & 1,177 & 24,75 \\
\hline Cera + GA & 22,84 & 3,50 & 1,315 & 26,50 \\
\hline $1-\mathrm{MCP}+$ cera $+\mathrm{GA}$ & 18,53 & 3,50 & 1,170 & 27,00 \\
\hline Reaplicação 1-MCP & 27,81 & 3,75 & 1,217 & 26,75 \\
\hline Teste F & NS & NS & NS & NS \\
\hline C.V. $(\%)$ & 18,262 & 13,129 & 8,608 & 9,586 \\
\hline
\end{tabular}

$\mathrm{NS}=$ teste $\mathrm{F}$ não significativo.

TABELA 3 - Efeito dos tratamentos sobre a perda de massa, teor de sólidos solúveis (SST), porcentagem de suco, acidez total titulável e cor da casca de lima ácida 'Tahiti' após 60 dias de armazenamento $\left(+3\right.$ dias a $\left.20^{\circ} \mathrm{C}\right) .{ }^{1}$

\begin{tabular}{|c|c|c|c|c|c|c|}
\hline \multirow[t]{2}{*}{ Tratamentos } & \multicolumn{2}{|c|}{ Cor da casca } & \multirow{2}{*}{$\begin{array}{c}\text { Perda de massa } \\
(\%)\end{array}$} & \multirow{2}{*}{$\begin{array}{l}\% \text { de } \\
\text { suco }\end{array}$} & \multirow[t]{2}{*}{ SST $\left({ }^{\circ}\right.$ Brix $)$} & \multirow{2}{*}{$\begin{array}{c}\text { Acidez total } \\
\text { Titulável }(\%) \\
\end{array}$} \\
\hline & Ângulo de cor $\left(h^{\circ}\right)$ & Croma & & & & \\
\hline Controle & $110,75 \mathrm{e}$ & $38,50 \mathrm{a}$ & $46,25 \mathrm{bcd}$ & $25,25 \mathrm{ab}$ & 8,50 & 6,00 \\
\hline 1-MCP & $111,75 \mathrm{de}$ & 30,75 cde & $54,75 \mathrm{a}$ & $27,25 \mathrm{a}$ & 8,50 & 6,25 \\
\hline Cera & $116,00 \mathrm{bc}$ & $31,25 \mathrm{bcd}$ & $41,25 \mathrm{~d}$ & $18,50 \mathrm{c}$ & 8,00 & 6,00 \\
\hline GA & $111,25 \mathrm{de}$ & $36,50 \mathrm{ab}$ & $52,25 \mathrm{ab}$ & $28,75 \mathrm{a}$ & 8,50 & 6,00 \\
\hline $1-\mathrm{MCP}+$ cera & $120,50 \mathrm{a}$ & 25,75 ef & $44,00 \mathrm{~cd}$ & $20,00 \mathrm{bc}$ & 8,25 & 5,75 \\
\hline 1-MCP + GA & $114,50 \mathrm{~cd}$ & $33,00 \mathrm{bcd}$ & $49,75 \mathrm{abc}$ & $24,75 \mathrm{ab}$ & 9,25 & 6,50 \\
\hline Cera + GA & $118,25 \mathrm{ab}$ & 28,00 def & $47,75 \mathrm{abcd}$ & $21,50 \mathrm{bc}$ & 8,50 & 6,00 \\
\hline $1-\mathrm{MCP}+$ cera $+\mathrm{GA}$ & $121,75 \mathrm{a}$ & $23,25 \mathrm{f}$ & $46,00 \mathrm{bcd}$ & $19,00 \mathrm{c}$ & 8,75 & 6,00 \\
\hline Reaplicação 1-MCP & $110,00 \mathrm{e}$ & $34,50 \mathrm{abc}$ & $51,50 \mathrm{ab}$ & $29,25 \mathrm{a}$ & 8,75 & 6,50 \\
\hline Teste F & $* *$ & $* *$ & $*$ & $* *$ & NS & NS \\
\hline C.V. $(\%)$ & 1,357 & 7,069 & 6,362 & 9,760 & 7,460 & 5,892 \\
\hline
\end{tabular}

${ }^{1}$ Médias seguidas de mesma letra na coluna não diferem entre si pelo teste de Tukey a $5 \%$.

$\mathrm{NS}, * * *=$ teste F não significativo ou significativo a 1 ou $5 \%$, respectivamente. 
TABELA 4 - Efeito dos tratamentos sobre o teor de vitamina C, índice tecnológico e "ratio" de lima ácida 'Tahiti' após 60 dias de armazenamento $\left(+3\right.$ dias a $\left.20^{\circ} \mathrm{C}\right) .^{1}$

\begin{tabular}{lccc}
\hline Tratamentos & $\begin{array}{c}\text { Índice } \\
\text { tecnológico } \\
(\text { SST x } \% \\
\text { suco } / 100\end{array}$ & "Ratio" & $\begin{array}{c}\text { Vitamina C } \\
(\mathrm{mg} \text { ácido } \\
\left.\text { ascórbico/100 } \mathrm{mL}^{-1}\right)\end{array}$ \\
\hline Controle & $3,75 \mathrm{~b}$ & 1,400 & 27,00 \\
1-MCP & $4,75 \mathrm{a}$ & 1,360 & 24,75 \\
Cera & $3,25 \mathrm{~b}$ & 1,362 & 24,25 \\
GA & $4,25 \mathrm{a}$ & 1,352 & 26,00 \\
1-MCP + Cera & $3,25 \mathrm{~b}$ & 1,410 & 25,25 \\
1-MCP + GA & $4,25 \mathrm{ab}$ & 1,332 & 29,75 \\
Cera + GA & $4,00 \mathrm{ab}$ & 1,380 & 28,00 \\
1-MCP + cera + GA & $3,75 \mathrm{ab}$ & 1,412 & 28,00 \\
Reaplicação 1-MCP & $4,25 \mathrm{ab}$ & 1,365 & 26,75 \\
\hline Teste F & $*$ & $\mathrm{NS}$ & $\mathrm{NS}$ \\
C.V. (\%) & 11,951 & 7,514 & 9,793 \\
\hline
\end{tabular}

${ }^{1}$ Médias seguidas de mesma letra na coluna não diferem entre si pelo teste de Tukey a $5 \%$.

$\mathrm{NS}, *=$ teste F não significativo ou significativo a $5 \%$, respectivamente.

\section{Zeiger, 2002)}

A aplicação de cera, por sua vez, possui como objetivo principal reduzir a perda de água a partir da casca (flavedo e albedo) e conferir brilho aos frutos. Entretanto, a depender da concentração utilizada pode alterar drasticamente a atmosfera interna nos frutos, com reduções excessivas de $\mathrm{O}_{2}$ e aumentos demasiados de $\mathrm{CO}_{2}$, o que pode conduzir ao processo de respiração anaeróbica e provocar alterações indesejáveis e distúrbios fisiológicos (Petracek et al., 1998). No presente trabalho, embora a cera tivesse reduzido a perda de coloração verde, foi detectada a presença de odor e sabor estranhos nos frutos. Provavelmente isto está associado com a modificação drástica da atmosfera interna, o que pode ter gerado teores elevados de etanol e acetaldeído. Em frutos cítricos, a presença de etanol e acetaldeído é aceitável em certos níveis, entretanto, altas concentrações destes produtos de fermentação podem causar sabores e odores desagradáveis que depreciam a qualidade do produto (Cohen et al., 1990). Cabe ressaltar que a quantidade de cera aplicada foi recomendação fornecida pela empresa fabricante. Assim, menores quantidades ou diluições da cera em questão devem ser estudadas em novos experimentos.

As poucas alterações físico-químicas, como teor de sólidos solúveis, acidez titulável, teor de vitamina $\mathrm{C}$, taxa respiratória, entre outras, indicam que a ação dos produtos aplicados é restrita ao albedo e flavedo do fruto, não havendo, possivelmente, uma difusão mais interna destes produtos. De fato, o fruto cítrico, além destas barreiras iniciais, apresenta a sua estrutura interna segmentada, com membranas semipermeáveis envolvendo estes segmentos e dificultado a entrada e saída de moléculas (Ting \& Roussef, 1986).

\section{CONCLUSÕES}

1) A cera é suficiente para retardar a perda de coloração verde da casca sob refrigeração a $10^{\circ} \mathrm{C}$. Entretanto, novas doses e diluições devem ser testadas para evitar alteração no sabor e aroma dos frutos.

2) O uso 1-MCP mantém a coloração verde até 30 dias de conservação refrigerada, enquanto que sua reaplicação após 30 dias não apresenta efeito para a manutenção da coloração verde da casca.

3) A aplicação de ácido giberélico mantém a coloração verde da casca até 30 dias de conservação a $10^{\circ} \mathrm{C}$.

\section{AGRADECIMENTOS}

À Fundação de Amparo à Pesquisa do Estado de São Paulo FAPESP, pela bolsa de iniciação concedida ao primeiro autor para a realização do presente trabalho (proc. $n^{\circ}$ 00/11499-6).

\section{REFERÊNCIASBIBLIOGRÁFICAS}

ABELES, F.B; MORGAN, P.W.; SALTVEIT, M.E. Ethylene in plant biology. 2 ed. San Diego: Academic Press, 1997. 414p.

BALDWIN, E.A. Citrus fruit. In: SEYMOUR, G.B.; TAYLOR, J.E.; TUCKER, G.A. (Eds). Biochemistry of fruit ripening. London: Chapman \& Hall, 1994. p. 255-271.

BARROS, S.A.; RODRIGUES, J.D.; RODRIGUES, S.D.; PEDRAS, J.F. Efeito do ácido giberélico e do uniconazole na fisiologia pós-colheita do limão 'Tahiti' (Citrus latifolia Tanaka). Revista Brasileira de Fruticultura, Cruz das Almas, v.13, n.3, p.223-226, 1991.

CHITARRA, M.I.; CHITARRA, A.B. Pós-colheita de frutos e hortaliças: fisiologia e manuseio. Lavras: ESAL/FAEPE, 1990.320p.

COHEN, E.; BEN-YEHOSHUA, S.; ROSENBERGER, I.; SHALON,Y.; SHAPIRO ARO, B. Quality of lemons sealed in high-density polyethylene film during long-term storage at different temperatures whith intermittent warming. Journal of Horticultural Science, Ashford, v.65, n.5, p.603-610, 1990.

DILLEY, D.R. Hormonal control of fruit ripening. HortScience, Alexandria, v.4, n.2, p.111-114, 1969

FAN, X.; MATTHEIS, J.P. Yellowing of broccoli in storage is reduced by 1-methylcyclopropene. HortScience, Alexandria, v.35, p.885- 887, 2000.

FIORAVANÇO, J.C. Efeito da aplicação de citocinina, cera e embalagem de polietileno na conservação de lima ácida'Tahiti' (Citrus latifolia Tanaka) em temperatura controlada. 1992, 159f. Dissertação (Mestrado em Fitotecnia) - Universidade Federal do Rio Grande do Sul, Porto Alegre, 1992.

GOLDSCHMIDT, E.E. Ripening of citrus and other non-climateric fruits: a role for ethylene. Acta Horticulturae, Leuven, n.463, p.325-334, 1997.

KAPLAN, H.J. Washing, waxing, and color-adding. In: WARDOWSKI, W.F.; NAGY; GRIERSON, W. (Eds.). Fresh Citrus Fruit. New York: AVI, 1986. p.379-395.

KLUGE, R.A.; SCARPARE FILHO, J.A.; JACOMINO, A.P.; PEIXOTO, C.P. Distúrbios fisiológicos em frutos. Piracicaba: FEALQ, 2001. 58p.

KU, V.V.V., WILLS, R.B.H., BEN-YEHOSHUA, S. 1-Methylcyclopropene can differentially affect the postharvest life of strawberries exposed to ethylene. HortScience, Alexandria, v.34, p.119-120, 1999.

McGUIRE, R.G. Reporting of objective colour measurements. HortScience, Alexandria, v.27, p.1254-1255, 1992.

PETRACEK, P.D.; DOU, H.; PAO, S. The influence of applied waxes on postharvest physiological behavior and pitting of grapefruit. Postharvest Biology and Technology, Waganingen, v.14, p.99-106, 1998.

SCHECHTER, S.; GOLDSCHMIDT, E.E.; GALILI, D. Persistence of $\left({ }^{14} \mathrm{C}\right)$ gibberellin $\mathrm{A}_{3}$ and $\left({ }^{3} \mathrm{H}\right)$ gibberellin $\mathrm{A}_{1}$ in senescing, ethylene treated citrus and tomate fruit. Plant Growth Regulation, Dordrecht, v.8, n. 3, p.243-253, 1989.

SILVA, J.A.A.; DONADIO, L.C. Reguladores vegetais na citricultura. Jaboticabal: Funep, 1997.38p. (Boletim Citrícola, 3)

SISLER, E.C.; SEREK, M. Inhibitors of ethylene responses in plants at the receptors level: recent developments. Physiologia Plantarum, Copenhagen, v.100, n.5, 577-582, 1997.

SPÓSITO, M.B.; MOURÃO FILHO, F.A.A.; KLUGE, R.A.; JACOMINO, A.P. Armazenamento refrigerado de frutos de limeira-ácida 'Tahiti' tratados com ácido giberélico. Revista Brasileira de Fruticultura, Jaboticabal, v.22, n.3, p.345-348, 2000.

TAIZ, L.; ZEIGER, E. Plant Physiology. 3. ed. Sunderland: Sinauer Associates, 2002. 690.

TING, S.V.; ROUSEFF, R.L. Citrus fruits and their products: analysis y technology. New York: Marcel Dekker, 1986. 293p.

VENDRELL, M.; PALOMER, X. Hormonal control of fruit ripening in climacteric fruits. Acta Horticulturae, Leuven, v.463, p.325-334, 1997.

WAKS, J.; SCHIFFMANN-NADEL, M.; LOMANIEC, E.; CHALUTZ, E. Relation between fruit waxing and development of rots in citrus fruit during storage. Plant Disease Reporter, St Paul, v. 69, n. 10, p. 869870, 1985. 